more largely in the public eye" ; and from this you naturally conclude that "if the nation thus does honour to the healer dead, it needs must follow that the healer living and working should be equally entitled to the respect and confidence of his fellow citizens." of course it should follow; and the public itself should be the first to recognise merit and to acknowledge that the class of men forming the medical profession were really worthy of and entitled to respect and confidence. Unfortunately, in some parts of the world the tendency of the population as a whole is to regard a medical practitioner and a shopkeeper as on a level. It is not for me to say why this is so-whether it is owing to any peculiar matter-of-fact way the people have of looking at things or to the fact that the medical men they have in their midst are not men to win their respect and confidence. Each may, perhaps, be a factor, although I am inclined to think, judging from my own experience, that the latter is the true fons et origo mati. Now, if anything could be done to rectify this state of matters it would be such a plan as I have ventured to suggest. We secure at once a better class of men as medical practitioners, we gain the respect to which we are fairly entitled, but which the public has hitherto withheId, we benefit our patients by our greater skill in our art, and we benefit ourselves by lessening competition and friction (an immense gain). In concluding your leading article on Dr. Pye-Smith's oration you say that "the sister profession of the law has set us a good example" in enforcing the great morals of its practice and increasing that concord of the legal profession which is so essential to its prosperity and its honour. I have ventured to suggest that it sets us a good example also in its rules for the admission of its intending students. Until such a rule, however, is passed by those in authority in matters medical it is strictly incumbent on the Royal Colleges to use that disciplinary control on the exercise of which their privileges and their monopolies were originally made con. tingent-a control which you are careful to indicate has been allowed to fall into desuetude. How, again, on this point is it with the legal profession? What machinery can the legal authorities not call into instant action if necessity arises? What man of them all is safe if he commits an unprofessional act? Can his name not be immediately struck off the roll? Hence, even if for no higher motive, a member of the legal profession has to be exceedingly careful to do that which is right, not merely in his own eyes, but in the eyes of all in his profession. In medicine there is no such safeguard, or, if there is, it is surely in abeyance; but my main object in this communication, as I have said, is to call attention to a definite plan having reference to the time before a man enters the medical profession, and it seems to me, judging from the tenour of public prints, that my idea is to the point and also timely. If it should meet your views and find its way into your columns, or you should think anything is to be made of the idea, it will be a great satisfaction to me to know that I have been the means of raising and upholding the status of the medical profession, and thereby benefiting it and the public alike. I am, Sirs, yours truly,

GEORGE A. LEGGE, M.A., M.D., C.M.

Somerset East, Cape of Good Hope, Dec. 11th, 1893.

* * Our correspondent is surely in error as to the entrance of a student into the legal profession.-ED. L.

\section{"EXCISION OF GUMMATA OF THE TESTICLE."}

To the Editors of THE LANCET.

SiRs, - With regard to the editorial comments upon a case of excision of a tumour from the testicle, published in THE LANCET, Nov. 4th, if the description had been less abbreviated the necessity for the operation would have been apparent, for the two tumours dissected out of the body of the testicle were both full of paltaceous semi-fluid material. Perhaps the word "gumma" in this connexion is more open to doubtI can only say that the age and history of the patient pointed that way; while the naked-eye characteristics were more those of softened subcutaneous gummata than of tuberculous cysts, of which I have had a large surgical experience in other parts of the body, though not in the testicles. Bat the special object in sending the case referred to was to show the ease with which the tumours were excised, leaving a healthy organ. Much has been written of late about conservative surgery of the ovary; I am under the impression that many castrations are performed for simple neoplasms of the testicle, which might be dissected out as in the case I recorded. I am, Sirs, yours truly,

Mission Hospital, Kashmir, Dec. 12th, 1883. ARTHUR NEVE.

\section{"CHLOROFORM IN NASAL GROWTHS."} To the Editors of THE LANCET.

SIRS,-Dr. Holloway, in his note in the last issue of THE LANCET on Chloroform in Nasal Growths, surely rather limits himself to one set of operators, for most certainly if he took a wider range be would find surgeons who take a much longer time than he allows. My experience as to the time for these operations is from thirty seconds to thirty minutes (half an hour). The shorter cases can be done easily with gasalene or continued with a whiff of ether as in slightly prolonged dental operations; the longer cases cannot be done with gas alone. If this be so-and as regards the length of time for the operation the surgeon can alone be responsible, and must be the best judge-what are we to administer to effectively anæsthetise the patient? My fairly large experience is that ether, with the preliminary gas, should be given to the full anæsthetisation of the patient; then, by an ordinary Junker, with two or three drachms of chloroform, we can continue the anæsthesia for any length of time required by blowing into the mouth. I dare say this proceeding looks a little com. plicated, if not fussy; but we have alone to consider the safety of our patient and must disregard anything that an onlooker may think. For myself I have not seen any untoward symptoms result from this method; but I am most emphatic on the need of commencing with gas and ether. All opera. tions about the nose and pharynx are of the gravest natare, chiefly from the possibility of asphyxiation from hæmor. rhage, and no one can undertake them with a light heart.

I cannot help thinking that in some of the cases reported as "misadventure from chloroform" the death is not always due to the anæsthetic ; but unfortunately they appear as such in the lay journals, and hence it behoves us to have them fully reported in our own journals that they may be thoroughly and professionally discussed. This surely is the great value of our new Society of Anæsthetists, where we can all fully report, in the most open manner, our failures and successes. I am, Sirs, yours truly,

Queen Anne-street, Jan. 8th, $1894 . \quad$ GEO. H. BAILEY.

\section{" THE DETERMINATION OF SEX."}

\section{To the Editors of THE LANCET.}

SIRs,-This subject, again opened up by Mr. Andrew Wilson in your issue of Dec. 30th, 1893, is one of the greatest interest and importance; and while his facts may be accepted his theory, built upon them, requires careful investigation and discussion. I think there is no doubt now as to the general acceptance of the truth of the facts as laid down by Mr. Wilson, corroborated as they are by the strong array of cases that he has adduced. Similar results are seen to follow in the lower animals (mammalia), as dogs, cattle \&c. where it is found that if impregnation takes place imme diately after the cessation of the "heat" (which corresponds to the human menstruation) the resulting offspring are more likely to be females than if the impregnation is delayed for some days. The interval of menstruation being shorter in the human mammal than in many of the others may stand in relation to a more rapid maturation of the ovum and, there fore, to a shorter time wherein the process that leads to determination of sex is carried out. And now as to $\mathrm{Mr}$. Wilson's theory. Unfortunately we have to construct a theory partly on supposition, for one of the chief factors missing-i.e., we do not know the time of the extrusion of the ovum from the ovary (ovulation) in relation to menstruation. I must here quote a few sentences from Mr. Wilson"s paper for the sake of reference. "I hold still that the orum which is fertilised pre-menstrually, being a stronger and more vital one, tends towards the male side, and tha the ovum which is fertilised post-menstrually, haring los mach of its vitality [the italics are mine], gets a bias towards the female side. Therefore, it needs a more vigorous orum in the quadruped [? mammal] to develop into a male than is required for a female conception. What I maintain is that given fertilisation, it is a question of vitality and nutrition on 
the part of the orum which decides the sex of the resulting embryo. ...... The embryo pursues for a time a straight patb, then deriates to the male or female side." What determines its deviation? Which is the straighter path? I do not agree with Mr. Wilson that "the impetus to this deviation is given at the commencement of its existence as a fertilised ovum": it is further back. "The longer fertilisation is delayed after its extrusion from the ovary the greater likelihood is there of the opum developing into a female embryo, and vice versâ." It is this theory, built apon the deritalisation of the ovum through menstruation, that I wish to combat.

Premising that Mr. Wilson's facts are true, which have been corroborated by other observers, that conception following very soon after menstruation results in a female embryo, and premising that the ovum comes fresh from the ovary soon after the cessation of the period, its then condition is that of early development-i. e., of quasi-immature growth-and if then fertilised it produces a female embryo, which, for want of a better expression, is of a lower type of derelopment; but after a time it attains a more mature stage, when its fertilisation results in the evolution of the higher type-i.e., the male. Following the same line of reasoning, how is it we so often see that girls are more impressed with the father's features and characteristics, and the boys with those of the mother? Is it not that the dominant energy of the father impresses the immature ovum and outweighs it, so to speak, in the balance of power, but in the case of the male embryo the result is obtained by the same paternal energy working on an ovum of a higher evolution-an ovum that has had more time of intra-maternal growth and so bears a greater proportion of maternal characteristics? I take it, therefore, it is not that menstruation weakens an ovum originally strong, and so "having lost much of its vitality," but that towarads the end of the inter-menstrual period the orum has gained in vitality, or rather has by evolution attained a more mature or higher grade. Before, however, we can formulate a theory that will carry conviction we must increase our knowledge as to the actual time in the menstrual cycle when ovulation takes place.

I am, Sirs, yours faithfully,

Harley-street, Jan. 2nd, 1894.

HEXWO0D SMITH

\section{"LEPROSY AND HEREDITY." \\ To the Editors of THE LANOHT.}

Sirs,-Dr. de Valencé, in the letter which he bas sent to you touching the matter of the lepers who are sent to India from Mauritius, does not dispute the accuracy of his own statement that these lepers are, as far as medical men can judge, healthy men when they arrive in the Mauritius, and that no inconsiderable number of them leave that colony and return to their homes in India incurable lepers. This they do at the expense and with the cheerful assent of the Government of Mauritius and so return to India to help to infect healthy people there with leprosy. Dr. de Valencé's beliefs and theories cbout "leprosy and heredity" do not alter the facts of the case. The people who believe in the hereditary transmission of leprosy, in the sense in which Dr. de Valencé believes in it, are so very few in number among those whose opinions on the subject are of any importance that it is unnecessary to deal with the matter. I am, Sirs, yours truly,

THE WRITER OF YOUR NOTICE OF THE REPORT OF THE ST. LAZARE LEPER ASYLUM.

\section{LIVERPOOL.}

(FroM oUb OWN CoRrespoNdent.)

\section{Hydrophodicl at Wavertree.}

McCH alarm was created at Wavertree, an eastern suburb of this city, by a report that on the 2 nd inst. several persons had been bitten by a rabid dog. Four boys were playing in Victoria Park when the dog furiously attacked them, biting three on the leg, one on the arm, and also biting a domestic servant on the leg, as well as tearing her clothes. The injured persons were all attended by Dr. Wearing, of Warertree, and have since been sent to Paris for treatment, one of the boys being sent by his father and the others by a fund raised by the local residents. The dog was destroyed by its owner, and on a post-mortem examination being made by Dr. Barron of Liverpool and Mr. Welsh, the veterinary surgeon of the district, it was found to be the subject of rabies The same dog also attacked Dr. Harvey of Wavertree, but fortunately the bite of the animal did not penetrate his clothes. A hurried meeting of the magistrates was convened on Saturday, and a muzzling order for the whole district of West Derby was issued.

\section{The Confinement of Inebriates.}

A melancholy instance of the necessity for the more effectual dealing with confirmed inebriates was disclosed at the city coroner's court on the 6th inst. 'The deceased, a married woman, had for years been so addicted to drink that she would pawn the furniture of the house bit by bit, as well as her husband's and her own cluthing. She actually died in a drunken state. Her husband, himself a sober man, gave evidence, and said that he had done his best to restrain her.

Hospital Sunday in Liverpool.

The second Sunday in the new year (Jan. 14th) will be the twenty-fourth anniversary of the observance of this institution in Liverpool, and, in accordance with their custom, the committee have published their annual report in pamphlet form, with many interesting details both of the Hospital Sunday and Saturday Funds. When the morement was begur in Liverpool it had been a "hardy annual" in Birmingham for about twelve years. It had begun in Carlisle, Manchester, and a few other places, but was unknown in London unti some years later. It may be fearlessly asserted that any difficulties which have been overcome in other towns and cities, or which have yet to be overcome, could not be more insidious or formidable than those which had to be encountered in Liverpool. But the perseverance of a few of its citizens, aided by THE LANCET and the local press, overcame all obstacles after two years' hard work, and the first Hospital Suncary collection took place on Jan. 8th, 1871. Its promoters had calculated upon obtaining a total of $\$ 4000$, and the amount actually realised was $\$ 4685$. It was, however, felt that it was only an earnest of what might be done, and that future years would see a considerable advance. For the next three years the collections rose to $£ 6823$, $£ 8124$, and $£ 8848$ respectively. In the year 1875 however, the sum fell to $£ 7462$, and fluctuated till 1879, when it dropped to $£ 6953$. Again, there was a rise in 1880 to f7558 and fluctuations occurred until in 1892 and 1893 the amounts were $£ 6410$ and $£ 6211$. In 1893 the weather on Hospital Sunday was very inclement, the streets being full of frozen snow and the cold most intense. Still, such a sum as $£ 6211$ is one which could not have been raised under such circumstances for any other objects save hospitals and other medical charities, to which it furnished a considerable proportion of their annual income; and therefore, although it was proposed to change the date, the committee judged it better to trust bravely to the future. It only remains to be added that the expenses of collection have always been extremely moderate, amounting yearly to less than 3 per cent. The committee, though comprising clergy and laity of all religious denominations, have worked together most harmoniously and their distributions to the various charities have given general satisfaction. It is confidently expected that with improved times the upward tendency will again be seen. Jan. 9th.

\section{MANCHESTER.}

\section{(From OUB OWN CoRRespondent.)}

$$
\text { Winting Weather. }
$$

After an unusually mild and open Christmas and New Year, severe weather set in about the midale of last week, and continued without intermission until yesterday evening, when a decided and welcome thaw suddenly took place. A large anti-cyclone has hovered over the neighbourhood of Manchester during the entire period that has elapsed since my last letter. The weather in Manchester has accordingly been misty, and at times dense fogs have overspread the city. From the middle of last week the air-temperature fell rapidly and steadily, until on Saturday night the terrestrial radiation thermometer indicated twenty degrees. of frost on the grass. This was at the City Meteorological Observatory in Oldham-road, but reports say that temperatures not much above these were recorded in certain country 